\title{
IMPROVEMENT OF FISHING THROUGH A KNOWLEDGE OF THE BREEDING HABITS OF FISHES
}

By Prof. Jacob ReighaRd, University of Michigan.

When the breeding season approaches most fishes leave their usual haunts and travel a longer or shorter distance to their breeding grounds. The distance travelled may be a few rods, as in the common sunfish, or it may be hundreds of miles, as in the salmon. In any case it brings the fish into new surroundings. Here it seeks certain definite conditions which vary with the species. Some of the fish require swift water, others quiet water; some seek a bottom of sand or gravel free from vegetation; others seek a bottom on which there is vegetation, so that they may attach their eggs to its rootlets (which they expose in making their nests) or hang them in masses from its branches. Each chooses a breeding ground suited to it. Compared to the total area frequented by the fish of any water, the breeding grounds are of limited extent. It results that the fish are crowded together on the breeding grounds as well as in their approach to the grounds. This, in many cases, affords unusual opportunity for their capture. The whitefish is a notable instance of this.

The sexes are brought together on the breeding grounds. At the instant when the eggs are laid there is, in all known cases, intimate contact of the body of the female with the bodies of one or more males in such a way that the vents of the two sexes are brought together. When the eggs are expelled the water is at the same instant filled with a cloud of milt. Every egg is at once surrounded by hundreds, thousands, perhaps millions of sperms, each seeking to penetrate it. Under such circumstances fertilization is practically certain. It is a popular error, from which fish culturists are not altogether free, that a large percentage of eggs remain unfertilized in nature and that these consequently die. It is commonly held that by resorting to artificial fertilization 
with its high percentage of impregnation, the fish culturist, by his method of fertilization alone, saves eggs that would otherwise perish. The fish culturist saves without a doubt, but not by his method of fertilization, for that is no more perfect than in nature. It is in truth, probably less perfect. In nature the eggs are laid only when thoroughly ripe and only in the presence of the fertilizing male. In spite of all his care the fish culturist, on the other hand, spawns females that are unripe and overripe and loses a considerable percentage in this way. $\mathrm{He}$ often finds eggs, naturally laid, a large percentage of which are dead, and may assume that these have not been fertilized. Under normal conditions the eggs that are unfertilized do not undergo cleavage and do not therefore form a blastoderm. If eggs are collected from natural waters shortly after they have been laid and while all of them are still living, it is found that practically all of them have undergone cleavage or that this has proceeded until a germinal disc has been formed. This in the early stages is the only criterion of fertilization. If the eggs are collected somewhat later many of them are dead and partly decayed and it is then impossible to tell whether or not they have been fertilized. To assume that they have not been fertilized is to ignore all that we know of eggs collected shortly after they have been naturally laid. I have collected from the natural waters the recently laid eggs of many fish and have failed to find any considerable number unfertilized. The gain of the fish culturist is therefore not in a higher percentage of fertilization, but rather in the protection afforded the eggs after fertilization.

The eggs may be laid in nests prepared by the male parent and are in that case protected by him until they hatch, or as in case of the black bass, until the young are well grown. Nearly one fifth of the species of fishes that occur in Michigan are known to build nests, and give their eggs, by this means, a protection analogous to that afforded by the fish-culturist. But the majority of fishes build no nests and their eggs suffer from many enemies. 
The features of interest to us in our present discussion of the breeding habits of fishes may be summarized as follows :

1. At the breeding season fishes migrate from their ordinary haunts to the breeding grounds.

2. Each species selects a breeding ground characteristic of it. It shows a preference with respect to the character of the water (warmer or colder, clear or turbid, quiet or running), with respect to the nature of the bottom (sand, gravel, marl, muck, mud) and with respect to the presence or absence of plants.

3. Both sexes are present at the same time on the breeding ground. Their bodies are in intimate contact at the moment of laying of the eggs and practically all eggs are fertilized.

4. Some species construct nests for the protection of the eggs. Others construct nests and guard the eggs. Others continue the guardianship for a longer or shorter time after the eggs have hatched. Most species do not construct nests and do not guard the eggs or young.

In order that fishes may thrive in any natural water it is necessary that there be sufficient food and that there be available breeding grounds suited to each species. Most fishes are not narrowly limited in their choice of food. They are capable, with few exceptions, of utilizing the available animal food. Their choice of breeding grounds is more limited. Yet in attempting to determine the suitability of a particular water for a given fish, far more attention has been paid to food than to breeding grounds. Of the two factors the latter is probably the more important.

\section{UTILIZATION OF OUR KNOWLEDGE OF THE BREEDING}

\section{HABITS OF FISHES.}

1. Selection of Waters in Which to Plant Fish. In the earlier days of fish culture in Michigan whitefish and wall-eyed pike were planted in many inland lakes. In a few of these the adult fish were afterward found, but in most of them the water remained as barren of the planted fish as before the planting. Conditions were evidently unsuitable, but in what respect? In most of the lakes thus planted it is probable that there was sufficient food for the adults of either of these species. But if suitable breeding grounds were lacking it is likely that conditions were in some way unsuited to the planted fry. In the case of the whitefish we have an imperfect knowl- 
edge of what are appropriate breeding conditions; in the case of the wall-eyed pike we are, I believe, still quite ignorant. It seems to me useless to introduce the fry into waters in which suitable breeding conditions are not known to exist. We need more knowledge. In the absence of this, it is best to plant only in waters in which the fish are known to be already breeding, and to introduce the young, if possible, on the breeding grounds. Small-mouthed bass require clear water and gravel bottom for breeding. Large-mouthed bass prefer plantgrown bottom and are more tolerant of turbid water. Suckers require running water and gravel bottom. It is unwise to introduce any of these forms into waters lacking in the conditions peculiar to its breeding activities. What is true of these species is equally true of others.

2. Preservation of Breeding Grounds. The ditching of streams and the lowering of lake levels by this or other means need not seriously affect the food supply of many fishes whose breeding grounds it destroys. The common sucker, red-horse, the stone-roller and several species of valuable bait minnows lay their eggs or build their nests on the ripples of the smaller streams. Ditching such a stream destroys these breeding grounds. They may be restored by the meandering of the stream which forms new ripples by depositing in its bed materials eroded from its banks. But in the meantime the increase of suckers or bait minnows may have been seriously checked. If the stream is kept straight by repeated ditching these fish may disappear from it.

Where lake levels are lowered the breeding grounds of the majority of fishes may be destroyed. The pike lays its eggs in the marshes or on the shallowest weedgrown bottom, often on over-flowed meadows. The basses and sunfishes and the bullheads build their nests on the shoals in water usually not over two feet deep. The blunt-nosed minnow, food for the large-mouthed bass and pike, the Johnny-darter and the miller's thumb, lay their eggs under stones very near the shore. When the shoals are laid bare the breeding grounds of all these 
forms are destroyed, or greatly limited. The new shore is usually of soft mud or marl without the stones needful for the small-mouthed bass and the smaller fishes mentioned above. From the shore the water deepens rapidly so that few shallows are left for any of the fishes. Lowering the lake level has thus destroyed or greatly limited both the food and the breeding grounds of the game fishes.

Raising of lake levels by damming their outlet may have a like effect by making the water over the shoals too deep for breeding fish. In this case new shoals are usually created by the overflow of flat lands and the fishes in time utilize these as breeding grounds.

It is evident that in all these cases the prolonged action of natural forces has brought the lakes and streams into such a condition that they afford to their native fishes both food and breeding grounds. The majority of fishes are more accurately adjusted to breeding conditions than to food. These conditions must be maintained or the fishes will greatly diminish or disappear.

3. Protection of Breeding Grounds. We are accustomed to protect fishes by forbidding fishing during the breeding season. The breeding season is not fixed by the calendar and may begin before the closed season or continue after it. The closed season is commonly too short to cover the breeding time, and the fishes suffer. In most waters there is always an open season for some fishes and the waters are never free from anglers, who are tempted to take whatever fish they can get, whether protected or not.

The breeding grounds, on the other hand, are of limited extent and may be definitely located by one who has knowledge of breeding habits. They may be marked by buoys and fishing on them prohibited while it is permitted elsewhere. For nest building fishes, like the basses, this method might prove more effective in preventing depletion than the present method of pond culture. It need not be more expensive. Under it fishing in a lake would be permitted during all seasons of the year, but 
prohibited on the breeding grounds during a period long enough to adequately cover all fluctuations of the breeding season.

The presence of fishermen on the lake during the breeding season in greater numbers than under the existing system, should serve to protect the breeding grounds, for they would watch one another. Each would tend to see that others did not encroach on the prohibited areas.

4. Construction of Breeding Grounds in Ponds That Lack Them. Shelford (1911) has said that "the breeding interests and the feeding interests of still-water food and game fishes are distinctly antagonistic." As a pond grows older the amount of rooted vegetation in it increases until the whole pond bottom becomes thickly covered by it. The decay of such vegetation adds to the water chemical substances which serve as food for the microscopic plants or algae (Pond, 1905). The algae form the basic food for the microscopic animals. These in turn form the food of younger fishes and from them a chain of nutrient relations leads up to the adult fishes. Consequently as a pond grows older and the number of rooted plants in it is increased it contains more fish food. But this same process which increases the food supply of fishes, tends to destroy the conditions necessary for their breeding. The bottom becomes so thickly covered with muck that there are no bare sand or gravel areas remaining and these are necessary for some fishes. At the same time the decay of the organic matter, which falls to the bottom, may so use up the oxygen in the bottom waters that fish eggs cannot live in them.

If the above statement is correct then it follows that old ponds, which contain few or no fish, may again be made productive. They may be rich in the basic fish foods, but lack the necessary breeding grounds. By removing a part of the vegetation in water of suitable depth so that sand or gravel bottom is exposed in some places and a sparse growth of plants permitted in other places, suitable breeding conditions may be restored. By 
the introduction of suitable fishes a barren pond thus treated might be made again productive.

I have attempted to show that through a knowledge of the breeding habits of fishes we may hope to preserve or increase our supply of fishes by one or more of the following means :

1. By wiser selection of the waters in which fish are to be planted.

2. By the preservation of existing breeding grounds.

3. By the prohibition of fishing on breeding grounds while permitting it in adjacent waters.

4. $\mathrm{By}$ the construction of breeding grounds in ponds from which they have disappeared through the operation of natural forces.

For the fisheries interests a knowledge of breeding habits appears to be more important than a knowledge of food habits. Yet our knowledge of breeding habits is still very meager. One of the purposes of the present paper is to stimulate an interest in them with the hope that thereby our knowledge may be increased.

PoNd, R. H.:

\section{LITERATURE CITED.}

1905-The Biological Relation of Aquatic Plants to the Substratum. U. S. Commission of Fish and Fisheries, Report of the Commissioner for the year ending June 30, 1903, pp. 482-586, 6 figures. Washington, 1905.

SHELFOR, V. E.:

1911-Écological Succession. III. A Reconnaisance of its Causes with Particular Reference to Fish. Biological Bulletin, Vol. XXII, pp. 1-38.

\section{DISCUSSION}

Prof. Ward, of Illinois: The substance of this paper must be very prominently in mind as it was continually emphasized in the paper by President Townsend and those of you who recall Prof. Dyche's paper of last year will remember that one of the very first things he considered in the construction of ponds was the maintenance of proper breeding areas for the fish. To have successful fish ponds we must take into account the habits of the animals to be kept in those ponds. I was asked some months ago to examine a pond installed by a southern Georgia fishing club, to tell them why they failed to get fish. The pond was just a receptacle containing a certain number of gallons of water, and without any shore area or plant growth whatever. The reason that fishes did not thrive was perfectly evident, but it had not occurred to the members of the club that the fish required any speciar place to breed. I am confident that many of the failures experienced in private culture are caused by lack of proper breeding places for the fish.

Mr. Nesuey, of New York: While working on Lake Erie I found just the condition mentioned by Professor Ward. The southern side of Lake Erie has become so contaminated by the large cities that the majority of the whitefish spawn on the Canadian side. The State Department of Fisheries was compelled to go over on the Canadian side to collect eggs for the reason that the bottom there was not polluted. 